\title{
Laparoscopic Enucleation of Benign Pancreatic Tumours
}

\author{
Ion C. PUIA ${ }^{1,2}$, Aida PUIA ${ }^{2 *}$, Paul G. CRISTEA ${ }^{1}$ \\ 1"Octavian Fodor" Regional Institute of Gastroenterology and Hepatology, 3rd General Surgery Clinic, 19-21 Croitorilor Street, Cluj-Napoca, \\ Romania;drpuia@yahoo.fr;paulgcristea@gmail.com \\ 2"Iuliu Hatieganu" University of Medicine and Pharmacy, 8 Victor Babes Street, Cluj-Napoca, \\ Romania;draidapuia@gmail.com (*correspondingauthor)
}

\begin{abstract}
Benign pancreatic tumour enucleations have been performed since 1996. Endocrine tumours (ET) are rare yet they represent about $2 / 3$ of the laparoscopic enucleations, a topic still in debate. The preoperative imaging routinely comprises a CT scan, but endoscopic ultrasound is mandatory for localizing the tumour and guided biopsy-aspiration. Trocars have to be positioned to avoid "fencing" with the instruments. A Kocher procedure may be necessary for accessing deep or posterior tumours. The bipolar electrocautery and harmonic scalpel ensure better haemostasis than the monopolar cautery hook. The raw surface can be covered with haemostatics or fibrin glue. The mean operating time is about two hours. Forced conversions, due mainly to haemorrhage or insufficient exposure, are uncommon (9\%). Pancreatic fistula, the main postoperative complication, affects up to one third of the patients and does not depend on the choice of dissection instruments, management of the remaining cavity or somatostatin use. The main risk factor is the location of the tumour at less than $2 \mathrm{~mm}$ from the main pancreatic duct. The necrotic pancreatitis, the pancreatic pseudocyst and the duodenal fistula contribute to a surgical morbidity up to $60 \%$. Although safe and technically feasible, enucleation might be considered as a procedure with high morbidity score.
\end{abstract}

Keywords: benign tumours, enucleation, laparoscopic, pancreas

\section{Introduction}

The laparoscopic approach in major pancreatic surgery dates back to the mid ' 90 , but it still represents an option only in few tertiary specialised centres due to the complexity of the approach (Underwood and Soper, 1999). However, in the light of general tissue preserving surgery, laparoscopic enucleation and atypical resection for benign pancreatic tumours have gained acceptance and have been performed since 1996 (Costi et al., 2013a). Enucleation may be defined as the removal of a mass by dissecting it around its limits, without resecting any healthy tissue.

Endocrine tumours (ET) are rare yet they represent about $2 / 3$ of the laparoscopic enucleations (Brient et al., 2012). Insulinoma and gastrinoma are the most common functional ET's (Kianmanesh et al., 2008). Mucinous and serous cystadenomas and other benign tumours appear in casereports (Giger et al., 2006). Schwannoma (Wu et al., 2005), fibrous tumour (Miyamoto et al., 2007), pancreatic polypeptide secreting tumours (PPomas) (Kuo et al., 2008) or dermoid cyst (Vermeulen et al., 1990) are limited findings.

Technical feasibility and short term efficacy are proven mostly by case reports and small retrospective multicentric studies. The largest unicentric data presents 29 consecutive cases of laparoscopic enucleations (Costi et al., 2013 a). The authors' personal experience is limited to a single case of serous cystadenoma.

Case selection and technical details related especially to the management of the raw surface after the removal of the mass are among the topics which raise interest (Zhang et al., 2016).

By reviewing the existing data on this topic, the authors tried to encourage the laparoscopic approach, which could be safely used in more cases than it is nowadays. The reasons for this are the optimised preoperative imaging, widely available intraoperative ultrasound and safe haemostatic devices.

\section{The preoperative assessment}

Preoperative imaging routimely includes a CT scan, but endoscopic ultrasound is mandatory for localizing the tumour and allowing, if considered necessary, a guided biopsy/aspiration (Costi et al., 2013 a). EUS-guided (Endoscopic ultrasound) fine needle tattooing is an alternative method of localization in case of lack of laparoscopic ultrasound (Vaidakis et al., 2010). In cases of 
394

cystic tumours ERCP (Endoscopic retrograde cholangiopancreatography) may be useful for showing no contact between the main pancreatic duct and the tumour (Mori et al., 1995).

\section{The surgical technique and procedure steps}

The semi-Fowler's supine position, with the legs in abduction, seems to be generally accepted. The disposition of the surgical team can vary considering the location of the tumour, the procedure performed and the individual preference. By changing the surgeon's position and tilting the table laterally access may be improved.

Two monitors, a harmonic scalpel, bipolar electrocautery forceps and routine laparoscopic instruments are necessary. A $0^{\circ}$ laparoscope held by a robotic arm guided by vocal control is recommended by experienced surgeons (Costi et al., 2013 a) but a $30^{\circ}$ optic may offer better perspective in difficult situations. The flexible laparoscopic ultrasound offers vital information on the position and relations of the tumour with the pancreatic duct and vessels.

A nasopancreatic drainage stent (NPDS) placed endoscopically prior to surgery helps to delineate the main pancreatic duct during ultrasonography (Misawa et al., 2013).

A right sided procedure aiming at the head and uncus necessitates 4-5 trocars in the right upper quadrant with at least one of $12 \mathrm{~mm}$. The appropriate rules concerning angles have to be followed in order to avoid "fencing" with the instruments.

The transsection of the gastrocolic ligament allows a wide access for the ultrasound transducer in the omental pouch. An important issue is the relation of the tumour with the main pancreatic duct. The preoperative duct stenting may facilitate a correct assessment and can reduce the risk of pancreatic fistula (PF) (Misawa et al., 2013). A Kocher maneuver may be necessary for accessing deep or posterior tumours. The supplemental dissection of the superior pancreatic margin allows an appropriate enucleation in selected cases (Costi et al., $2013 \mathrm{a})$.

The left-sided procedures (pancreatic neck-body-tail) necessitate 6 trocars placed on the midline and sideways on the left and right mid-axillary line. The access is gained through the gastrocolic, or rarely, through the hepatogastric ligament (Kang et al., 2008). After performing the ultrasound, if the distance to the duct is safe, the superior and inferior margins of the pancreas are dissected in order to allow the enucleation (Costi et al., 2013 a).

The enucleation is performed by blunt and sharp dissection. Bipolar electrocautery and harmonic scalpel ensure better hemostasis than the monopolar cautery hook. A holding suture may allow a progressive "extraction" of the mass as circumferential dissection progresses in depth (Kang et al., 2008). The dimensions of the tumour do not represent a challenge by itself, the largest reaching up to $60 \mathrm{~mm}$ (Costi $e t$ al., 2013 a). Suturing or not the remaining cavity, or covering the raw surface with hemostatic products, relies on the judgment of the surgeon who has to consider several factors: the quality of the parenchyma, the size of the cavity and bleeding risk. The raw surface can be covered with Tachosil, Surgicel, Floseal (Costi et al., 2013 a) or fibrin glue (Singh et al., 2006). A Roux-en-Y limb to drain the enucleation bed is seldom used, even in open enucleation (Inchauste et al., 2012).
After enucleation pancreatography through the NPDS may detect injury to the main pancreatic duct. If branches of pancreatic duct are identified, ligation is recommended (Misawa et al., 2013).

The selective or even routine drainage is also endorsed.

\section{Discussion}

Although the laparoscopy has gained wide acceptance in most areas, enucleation in pancreatic surgery is still a topic currently in debate (Zhang et al., 2016).

Regarding the case selection, preoperative process that confirms malignant tumours have to be excluded, whereas those of uncertain nature may benefit of enucleation pancreatic surgery. In this situation, the biopsy of a small, deep lying, tumour, is usually difficult, so surgery may bring diagnose and treatment. If malignancy is found especially with positive margins, conversion or reoperation is mandatory (Costi et al., 2013 a). Non-invasive intraductal papillary and mucinous neoplasm may be approached, but the rate of PF is as high as 54\% (Blanc et al., 2008).

The operative set-up may vary regarding the optimal position of the surgeon and the number and placement of trocars. The general idea is to adapt to the specific conditions of a certain case, without clinging to a standard position or number of trocars.

Intraoperative ultrasound is mandatory for localizing the tumour and to detect multiple neoplasia (Singh et al., 2006). Experienced teams are seldom unable to localize intraoperatively the tumour (Costi et al., $2013 \mathrm{a}$ ).

If learning curve and malignant cases are excluded, forced conversions, due mainly to haemorrhage or insufficient exposure, are rare (9\%) (Costi et al., 2013a). Conversions, if malignancy is confirmed on frozen section, have to be regarded as a proof of sound judgment.

The pancreatic fistula is the main postoperative complication. Due to various definitions of PF data are heterogeneous. Papers reporting PF according to the conference of the International Study Group of Pancreatic Fistula (ISGPF) have up to one third of the patients affected by this complication. PF incidence does not depend on the choice of dissection instruments, management of the remaining cavity (suture, omentoplasty, local haemostats) or somatostatin analogue use (Costi et al., 2013 a). A risk factor for PF is the location of the tumour at less than $2 \mathrm{~mm}$ from the main pancreatic duct (Brient et al, 2012). The best laparoscopy procedure does not reduce the PF rate of enucleations, as open series report a similar PF rate (Brient et al., 2012; Inchauste $e t$ al., 2012).

Other specific complications may include necrotic pancreatitis, pancreatic pseudocyst and duodenal fistula (Costi et al., 2013 a). The overall surgical morbidity of open enucleations seems to be lower (28.3\% vs. 60\%) (Hackert $e$ al., 2011).

The mean operating time of enucleations is about 2 hours. The blood loss is usually minimal. However, losses of up to $1,500 \mathrm{ml}$ have been communicated by experienced teams (Costi et al., 2013 a).

Considering right vs. left-sided laparoscopic enucleations the results are different. A longer duration (178 vs. 132 minutes), but more important a higher morbidity (64\% vs. 
$45 \%$ ) and longer hospital stay (26 vs. 9 days) demonstrate that head-uncus locations should be approached with caution even by experienced teams (Costi et al., 2013 b).

The mean postoperative days does not reflect the immediate outcome, as patients may be discharged with a patent PF (Sweet et al., 2007).

\section{Conclusions}

Considering the recent literature data, the optimal way of sectioning and managing the raw pancreas procedure, in order to reduce the risk of PF, remains the main goal of enucleation. Although safe and technically feasible, enucleation represents a procedure with high morbidity. Controlled randomized studies would be useful to assess the method.

\section{References}

Blanc B, Sauvanet A, Couvelard A, Pessaux P, Dokmak S, Vullierme MP, Belghiti J (2008). Résections limitées du pancréas pour tumeur intracanalaire papillaire et mucineuse non invasive. Journal de Chirurgie 145(6):568-578.

Brient C, Regenet N, Sulpice L, Brunaud L, Mucci-Hennekine S, Carrère N, Mirallié E (2012). Risk factors for postoperative pancreatic fistulization subsequent to enucleation. Journal of Gastrointestinal Surgery 16(10):1883-1887.

Costi R, Randone B, Mal F, Basato S, Lévard H, Gayet B (2013). Laparoscopic minor pancreatic resections (enucleations/atypical resections). A long-term appraisal of a supposed mini-invasive approach. Wideochirurgia i Inne Techniki Małoinwazyjne 8(2):117-129.

Costi R, Randone B, Mal F, Basato S, Lévard H, Gayet B (2013). A critical appraisal of laparoscopic pancreatic enucleations: rightsided procedures (Pancreatic Head, Uncus) are not mini-invasive surgery. Surgical Laparoscopy, Endoscopy and Percutaneous Techniques 23(6):524-531.

Giger U, Michel JM, Wiesli P, Schmid C, Krähenbühl L (2006). Laparoscopic surgery for benign lesions of the pancreas. Journal of Laparoendoscopic and Advanced Surgical Techniques. 16(5):452-457.

Hackert T, Hinz U, Fritz S, Strobel O, Schneider L, Hartwig W, Büchler MW, Werner J (2011). Enucleation in pancreatic surgery: indications, technique, and outcome compared to standard pancreatic resections. Langenbeck's Archives of Surgery 396(8):1197-1203.

Inchauste SM, Lanier BJ, Libutti SK, Phan GQ, Nilubol N, Steinberg SM, Hughes MS (2012). Rate of clinically significant postoperative pancreatic fistula in pancreatic neuroendocrine tumors. World Journal of Surgery 36(7):1517-1526.

Kang CM, Lee KG, Pyo JY, Lee SW, Kim KS, Choi JS, Kim BR (2008). Laparoscopic enucleation of a nonfunctioning neuroendocrine tumor of the pancreas. Yonsei Medical Journal 49(5):864-868.
Kianmanesh R, O'toole D, Sauvanet A, Ruszniewski P, Belghiti J (2005). Traitement chirurgical des tumeurs endocrines gastroentéro-pancréatiques, [Surgical treatment of gastric, enteric, and pancreatic endocrine tumors]. Journal de Chirurgie (Paris) 142(3):132-149.

Kuo SC, Gananadha S, Scarlett CJ, Gill A, Smith RC (2008). Sporadic pancreatic polypeptide secreting tumors (PPomas) of the pancreas. World Journal of Surgery 32(8):1815-1822.

Misawa T, Imazu H, Fujiwara Y, Kitamura H, Tsutsui N, Ito R, Yanaga K (2013). Efficacy of nasopancreatic stenting prior to laparoscopic enucleation of pancreatic neuroendocrine tumor. Asian Journal of Endoscopic Surgery 6(2):140-142.

Miyamoto H, Molena DA, Schoeniger LO, Haodong Xu (2007). Solitary fibrous tumor of the pancreas: a case report. International Journal of Surgical Pathology 15(3):311-314.

Mori K, Takeyama S, Hirosawa H, Watanabe T, Taniya T, Arakawa H, Nakanuma Y (1995). A case of macrocystic serous cystadenoma of the pancreas. International Journal of Pancreatology 17(1):91-93.

Singh N, Lo CY, Chan WF (2006). Laparoscopic enucleation of a nonfunctioning neuroendocrine tumor at the head of the pancreas. Journal of the Society of Laparoendoscopic Surgeons $10(2): 259-262$.

Sweet MP, Izumisato Y, Way LW, Clark OH, Masharani U, Duh QY (2007). Laparoscopic enucleation of insulinomas. Archives of Surgery 142(12):1202-1204.

Underwood RA, Soper NJ (1999). Current status of laparoscopic surgery of the pancreas. Journal of Hepato-Biliary-Pancreatic Surgery 6(2):154-164.

Vaidakis D, Karoubalis J, Pappa T, Piaditis G, Zografos GN (2010). Pancreatic insulinoma: current issues and trends. Hepatobiliary and Pancreatic Diseases International 9(3):234-241.

Vermeulen BJ, Widgren S, Gur V, Meyer P, Iselin C, Rohner A (1990). Dermoid cyst of the pancreas. Case report and review of the literature Gastroentérologie Clinique et Biologique 14(12):1023-1025.

Wu YL, Yan HC, Chen LR, Chen J, Gao SL, Li JT (2005). Pancreatic benign schwannoma treated by simple enucleation: case report and review of literature. Pancreas 31(3):286-288.

Zhang RC, Zhou YC, Mou YP, Huang CJ, Jin WW, Yan JF, Liao Y (2016). Laparoscopic versus open enucleation for pancreatic neoplasms: clinical outcomes and pancreatic function analysis. Surgical Endoscopy 30(7):2657-2665. 